\title{
REVISIÓN DE UN ARTÍCULO RECIENTE DE DÍEZ-GUTIÉRREZ (2014) Y REVISIÓN CUALITATIVA DE LOS VIDEOJUEGOS ANALIZADOS EN DíEZ-GUTIÉRREZ ET AL. (2004)
}

\author{
Pedro Vázquez-Miraz \\ pedro.vazquez@udc.es \\ Universidad de A Coruña- España
}

Recibido: 22-01-2016

Aceptado: 24-05-2016

\section{Resumen}

Presentamos en este artículo, una revisión teórica del artículo "Video games and genderbased based violence" (2014), el cual presenta una interesante revisión de determinados videojuegos, en función de sus contenidos sexistas de carácter violento. Si bien la calidad del artículo es brillante, el texto adolece de algunos errores, como una escasa revisión de videojuegos, aspecto que contrasta con el trabajo realizado por Díez-Gutiérrez et al. (2004). Sobre este último texto, también se ha realizado una serie de determinadas puntualizaciones desde una perspectiva cualitativa: la propia experiencia de un jugador de videojuegos.

Palabras Clave: Videojuegos, violencia de género, educación, comunicación, sexismo.

\begin{abstract}
This paper presents a theoretical review about the article "Video games based and genderbased violence" (2014), which presents an interesting review of certain video games, depending on their sexist and violent nature. Although this paper is brilliant, the article has some errors as a limited review of video games; something that contrasts with another paper by Díez-Gutiérrez (Díez-Gutierrez et al., 2004). In this latest paper, we also have carry out some clarifications from a qualitative perspective: the experience of a video game player.
\end{abstract}

Keywords: Video games, gender violence, education, communication, sexism. 


\section{Introducción}

El objetivo de este artículo de investigación es la de presentar una revisión sobre los datos que aportan dos textos científicos relacionados con el mundo de los videojuegos que ha escrito un prestigioso académico de reconocida carrera investigadora, basándose únicamente en la constatación de datos empíricos que presentan los documentos tales como nombres y descripciones; información que cualquier persona que haya jugado a los videojuegos que se mencionan, podría corroborar fácilmente la veracidad de tal información.

Finalmente se termina el artículo con una llamada al debate sobre la obsolescencia y los límites del conocimiento científico en el ámbito de los game studies frente al saber no científico de la comunidad de aficionados del mundo de los videojuegos.

\section{Revisión del artículo de Díez-Gutiérrez (2014)}

\subsection{Resumen del artículo de Díez-Gutiérrez (2014)}

Díez-Gutiérrez (2014) inicia su artículo nombrando la importante ley orgánica 1/2004 del 28 de Diciembre, de Medidas de Protección Integral contra la Violencia de Género de España, ley que definió legalmente el concepto violencia de género en ese país, para posteriormente asociar esa legislación con una serie de videojuegos que presentan en sus contenidos claras distinciones sexistas; siendo el exponente máximo de estas discriminaciones, las situaciones de violencia de género que algunos materiales de ocio representan, de forma más o menos explícita. El artículo continúa haciendo un repaso histórico de los videojuegos que están basados en la violencia de género, desde el juego Custer's Revenge (creado en 1982), los múltiples videojuegos relacionados con la temática anime, hasta un gran éxito de ventas como la saga del Grand Theft Auto, terminando con una profunda reflexión sobre los límites entre el compromiso que tienen las autoridades en erradicar las discriminaciones sexistas en los productos de ocio, la libertad que tienen las personas para poder comprar artículos machistas con un alto contenido violento y los intereses económicos de las multinacionales de la industria de los videojuegos (Díez-Gutiérrez, 2014).

\subsection{Videojuegos sexistas vs. videojuegos pornográficos}

Uno de los errores que padece el artículo de Díez-Gutiérrez (2014), es el de equiparar los videojuegos pornográficos con los videojuegos generalistas que presentan características sexistas o introducen la violencia de género en sus contenidos, pues aunque la distinta 
jurisdicción española, en muchas ocasiones agrupa los videojuegos violentos, sexistas o pornográficos en una misma categoría, en función de su contenido (Pastor, 2015); no distinguir en un texto científico entre un videojuego de ocio (un producto de masas dirigido generalmente a un público infanto-juvenil), y un videojuego pornográfico (un producto de índole erótica dirigido a un público adulto y más selectivo), es una equivocación que impide realizar una mejor interpretación sobre la presencia de conductas y actitudes sexistas en los videojuegos.

Si bien los estudios sobre los efectos negativos del excesivo uso de los videojuegos (Etxeberria, 2008; Muros, Aragón y Bustos, 2013; Sánchez Rodríguez, Alfageme y Serrano, 2010 citados en Ameneiros y Ricoy, 2015), los análisis sobre la gran cantidad de contenido violento que presentan estos productos de ocio (Díez-Gutiérrez, Terrón y Rojo, 2001), las investigaciones que tratan sobre el fuerte sexismo que impregnan sus contenidos (DíezGutiérrez et al., 2004; Guerra y Revuelta, 2015) o la presencia de estos contenidos juntos: la violencia sexista (Kearney y Pivec, 2007), son amplios y diversos; se ha pasado de una confusión teórica inicial a la hora de analizar este tipo de contenidos audiovisuales, a la creación de una taxonomía clara y concisa (Belli y López, 2008; Pérez, 2011), que permite diferenciar lo que es un estudio científico sobre videojuegos y lo que no lo es (Mäyrä, 2008; citado en Navarrete, Gómez y Pérez, 2014), definiéndose los denominados Game Studies como "investigaciones centradas en desvelar las claves de este medio expresivo y sus diversas implicaciones culturales, ya sean de naturaleza social, educativa o industrial" (Navarrete, Gómez y Pérez, 2014: 110).

No es la meta de este artículo realizar un análisis teórico acerca el concepto de sexismo y la violencia de género que está presente en la industria de los videojuegos, pero de forma anecdótica, se puede comentar uno de los ejemplos sexistas más claros y evidentes, que fue analizado en numerosas investigaciones: el caso de Lara Croft (Del Moral, 2001; Millán, 2001; Díez-Gutiérrez et al. 2004; Burguess, Stermer y Burguess, 2007; Guerra y Revuelta, 2015).

Lara Croft, el personaje femenino de la saga de videojuegos Tomb Raider, es la imagen prototípica de una heroína fuerte y ágil que se diseñó pensando que un juego de acción protagonizado por una mujer, sería una buena forma de atraer el segmento femenino al mercado de los videojuegos (Cassel y Jenkins, 1998 citados en Burguess, Stermer y Burguess, 2007); pues Tomb Raider, fue el primer juego de acción que presentaba una mujer con un papel principal para las jugadoras (Burguess, Stermer y Burguess, 2007). Lamentablemente, Lara Croft, en vez de convertirse en una figura reivindicativa del rol activo de la mujer, acabó siendo una fantasía masculina hipersexualizada (Kennedy, 2002), pues debido a un error de programación, hubo una gran desproporción en el tamaño de los pechos de esta protagonista respecto el resto de su cuerpo (Guerra y Revuelta, 2015), y cuando el videojuego salió a la venta, la mayoría de sus compradores fueron varones (Jenkins, 1998 citado en Guerra y Revuelta, 2015). Cierto es que la evolución morfológica posterior de Lara Croft fue muy positiva, ya que el personaje se hizo más realista y menos estereotipado a nivel sexual (Guerra y Revuelta, 2015), aunque en la actualidad, también se produce en este entorno evoluciones en la 
dirección contraria, como el caso del cambio sufrido por la protagonista del clásico videojuego Metroid o la presencia de las mujeres en los existentes videojuegos de lucha 1 vs. 1. En definitiva, el rol de la mujer en los videojuegos no suele ser el de protagonista, más bien se caracteriza por encuadrarse en una lista de personajes muy estereotipados como los de mujertrofeo, mujer-fatal, villana manipuladora y mujer-florero (Guerra y Revuelta, 2015).

Respecto los inicios de los videojuegos pornográficos; en occidente, los primeros productos de este estilo surgieron en los EE.UU en la década de los 80 a manos de la compañía japonesa Atari, siendo uno de estos juegos Custer's Revenge, juego cuyo objetivo no era otro que el de controlar al malogrado general americano, esquivando las flechas que le lanzaban sus enemigos y llegar al extremo de la pantalla, donde el personaje obtenía su ansiado premio: el de violar a una india cautiva (Yao, Mahood y Linz, 2010). Si bien es cierto que Atari hizo algunos juegos más de esta categoría, tildar de éxito comercial una venta de 80.000 unidades como hace Díez-Gutiérrez (2014) es como mínimo discutible, más si se considera a los videojuegos pornográficos como un género similar al resto, pues si se compara bajo los mismos parámetros comerciales, las ventas de Custer's Revenge con las de E.T, juego de limitada calidad (Lambert y Villota, 2013), creado por la misma compañía y lanzado al mercado el mismo año que Custer's Revenge, y que es considerado como el peor videojuego de la historia, siendo uno de los fracasos económicos más importantes de Atari (a pesar de haber vendido más de un millón de unidades); lo que produjo, entre otros factores, la quiebra de la compañía nipona en 1983 (Lambert y Villota, 2013). Por último, en el artículo de Díez-Gutiérrez (2014) se continúa el análisis de la evolución de este tipo de videojuegos, desarrollando una extensa recopilación de productos recientes de esta temática adulta, los cuales tienen su origen en la animación audiovisual de ese país asiático: el anime, que a su vez, procede del manga (Schodt, 1983; citado en Grigsby, 1998).

En referencia a España, la única polémica que alcanzó una difusión mediática relevante asociada con este tipo de material, fue la transmisión en las madrugadas de anime erótico (hentai) por parte de una televisión privada en el año 2006, recibiendo quejas de algunos miembros de la sociedad sobre la idoneidad de emitir ese tipo de programas, lo que obligó a la compañía a dejar de emitir esos dibujos (Periodista Digital, 27-09-2006). Las críticas se centraron en una de esas animaciones: "Daiakuji (El mercenario del sexo)", en la que una presunta niña menor de edad, era violada por un hombre adulto (Periodista Digital, 27-092006); si bien, la cadena de televisión se justificó con un argumento que Diez-Gutiérrez (2014) advertía en su artículo; la referencia en los videojuegos pornográficos de estilo bishōjo, en que la chica, a pesar de tener una apariencia física similar a la de una niña, era mayor de edad, siendo esto una triquiñuela argumental que evitaba problemas legales a la hora de crear y/o emitir estos productos. 


\section{Revisión de los videojuegos analizados en Díez-Gutiérrez et al. (2004)}

Si bien en el resumen de este artículo se ha comentado que la revisión de videojuegos realizada por Díez-Gutiérrez (2014) era bastante limitada en número, eso no quiere indicar que el autor desconociera las restricciones de su propio estudio respecto el tema de la violencia y el sexismo en los videojuegos, pues solo con el hecho de recordar la extensa formación y algunos trabajos de la amplia obra del autor, como el trabajo de Díez-Gutiérrez et al. (2004), siendo éste un documento donde se compararon, a través de un análisis videográfico, más de 250 videojuegos; la posibilidad de estar analizando trabajos de un autor que no maneja una amplia y correcta base de datos, se rechaza por completo. Para Díez-Gutiérrez et al. (2004), el sexismo explícito en los videojuegos se presenta de múltiples formas: desde la presentación de las mujeres con los roles sexuales tradicionales (siendo el clásico ejemplo la princesa Peach de la saga Mario Bros), hasta una masculinización de los personajes femeninos que exaltan roles masculinos (como la ya citada Lara Croft); mientras que el sexismo implícito lo forma la cultura y el ambiente de los videojuegos que presentan la idea distorsionada de los roles sexuales, siendo los roles masculinos positivos y los femeninos negativos, situación que Díez-Gutiérrez et al. (2004) denominan como la "cultura macho", cultura que fácilmente se puede asociar con otros conceptos psicosociales como la cultura del honor (López-Zafra, 2007).

A continuación se presenta un análisis de esta profunda revisión, pero más que incidir en la perspectiva científica que permite analizar la violencia y/o el sexismo de tales productos, se prefiere indicar la simple veracidad de algunos datos que se exponen de los videojuegos analizados desde una perspectiva más subjetiva: la del sujeto que ha jugado a algunos de los videojuegos que fueron analizados; pues si la descripción es equivocada, las conclusiones que se concluyen pierden rigurosidad.

\subsection{Correcciones al análisis videográfico de Díez-Gutiérrez et al. (2004)}

- Half Life: la visión que presenta el texto de la enigmática figura del administrador, como un simple agente del gobierno, se basa en un simple error de doblaje al castellano, subsanado en su secuela; pues en la versión original del videojuego en inglés, este personaje habla de forma extraña, haciendo sospechar al jugador, de que este misterioso personaje no es un ser humano.

- Mario Kart: el texto erróneamente hace referencia a Super Mario Kart, juego de Super Nintendo, donde el personaje de la princesa Peach de la saga Mario Bros, sigue teniendo el mismo formato estereotipado, lo cual, produce el rechazo de muchos jugadores (Díez-Gutiérrez et al., 2004). El texto supone la presencia de características homogéneas en todos los personajes del juego, algo que es falso, pues éstos se 
diferencian por pares, teniendo (por ejemplo) la princesa Peach y Yoshi las mismas características a la hora de ser manejados por los jugadores, pero presentando diferencias con Koopa Troopa y Toad.

- Los Sims: en el texto, en referencia con el papel de la mujer, respecto este juego de simulación de la vida real se nos informa de lo siguiente:

"Evoluciona dentro de un continuo de valores cerrados según esos cánones (al igual que el hombre): de chica soltera moderna a madre trabajadora responsable. Dentro de ello cabe la posibilidad de casarse, pero no da cabida a otro tipo de posibilidades como por ejemplo ser madre soltera, lesbiana, ser adúltera, etc.” (Díez-Gutiérrez et al., 2004: 121).

La anterior afirmación es una falacia, pues el juego permite que tanto hombres como mujeres tengan relaciones amorosas (heterosexuales y homosexuales) una vez que se haya alcanzado un nivel de amistad muy elevado entre dos personas del juego, sin distinción de que las personas estén casadas o no.

- $\quad$ Age of Empires II: según los autores, en este videojuego de estrategia se reproduce la historia masculina tradicional desde un único punto de vista maniqueo, algo que se debe considerar inexacto, pues en la campaña de Saladino, se nos introduce a la época de la Tercera Cruzada desde la visión de un narrador cristiano, mientras que en el juego se maneja al ejército sarraceno y al finalizar la campaña se hace un profundo alegato por la convivencia pacífica de culturas.

- Zelda: se aprecia un error en la descripción del protagonista principal de esta famosa saga de videojuegos (Link), al que se describe como un elfo, algo que es una equivocación, pues la saga desde sus inicios ha pretendido diferenciarse (por propio interés) usando sus propios términos para describir las razas que habitan el mundo imaginario del juego; siendo el par de los elfos, los kokiri, y el de los humanos, los hylianos; siendo Link un hyliano que es criado como si fuera un kokiri.

- Jedi Knight: presencia de errores ortográficos de lugares de la saga de Star Wars (Llavin 4 en vez de Yavin 4), obviando la revisión la estructura básica de los primeros juegos de esta saga; pues en función de los propios actos que realice el jugador, el protagonista se dirigirá hacia el lado oscuro de la fuerza o hacia las fuerzas del bien.

- Mafia: presencia de errores ortográficos (Morillo en vez de Morello), el texto afirma que el papel de las mujeres en este videojuego se limita a matar prostitutas que son confidentes de clanes mafiosos rivales, siendo esa descripción una visión sesgada, pues en el juego el protagonista se casa y tiene una hija, siendo una de sus máximas 
aspiraciones, la de asegurarles protección y seguridad; mostrando (ocasionalmente) compasión y empatía por otras personas, aún a riesgo de su vida propia.

- Patrician III: este juego de simulación económica inspirado en la liga hanseática, se define en el texto como "la lógica del capitalismo industrial de hace cien años, compra barato, vende caro" (Díez-Gutiérrez et al., 2004: 239), descripción inexacta, pues en el juego (que no permite interactuar como una comerciante femenina) se tiene un rol más activo (creando industrias, construyendo casas para la población, realizando actos filantrópicos, etc.), permitiéndole al jugador elegir y dirigir su papel hacia las actividades delictivas o hacia el comercio tradicional.

\subsection{Conclusiones al análisis videográfico de Díez-Gutiérrez et al. (2004)}

La vasta revisión de Díez-Gutiérrez et al. (2004) presenta críticas sesgadas por un patrón ideológico y no científico; ejemplo de ello son las opiniones realizadas a la saga española Commandos, pues Díez-Gutiérrez et al. (2004) critican la escasa información que se le da al jugador por las causas que llevaron a la situación de la II Guerra Mundial y los motivos por lo que los protagonistas luchan contra las tropas del Eje, pues si se tiene en cuenta que un videojuego no aspira a ser una clase magistral de historia, se puede considerar que el juego proporciona suficiente información acerca los motivos de porque se inicia el conflicto bélico y sus consecuencias (vídeos incluídos); otra opinión sesgada de forma muy evidente es la realizada a los videojuegos Los Sims y la saga SimCity, pues según Díez-Gutiérrez et al. (2004), estos juegos simplemente fomentan un consumismo mercantilista neoliberal. Otras críticas, simplemente se podrían considerar injustas, como las que están dirigidas al escaso papel de la mujer en videojuegos que representan épocas históricas antiguas como las sagas de Age of Empires o Medieval Total War (DíezGutiérrez et al., 2004), pues el papel de la mujer en los períodos pasados de la historia, consistía en la tradicional sumisión de la hembra respecto al varón y difícilmente juegos que intentan ser algo realistas, pueden representar algo que no sucedía en la realidad; o las opiniones más furibundas que rechazan videojuegos neutros como los Lemmings porque en ellos se reproducen de forma implícita de estereotipos sexistas debido a que "los trabajos que se les atribuyen contribuyen a mantener los estereotipos tradicionales achacados a los hombres y a las mujeres" (Díez-Gutiérrez et al., 2004: 434).

En relación al papel de la mujer en los videojuegos, la conclusión que hace DíezGutiérrez et al. (2004) es la siguiente: la mujer en el videojuego o no existe, o es tratada de forma estereotipada o es masculinizada, siendo imposible lo contrario, es decir, que las figuras masculinas en los videojuegos se presenten de forma más feminizada.

Se nos plantea, por lo tanto la siguiente pregunta: ¿habría alguna posibilidad real de hacer un videojuego del clásico género de aventuras de acción que tuviera como 
protagonista a una mujer y que no fuera sexista? Las posibilidades teóricas que se manejan son las siguientes:

- Si la protagonista actúa como el prototipo del hombre de acción, la mujer se estaría masculinizando, siendo un simple cambio en el género del protagonista.

- Si la protagonista actúa como el prototipo de una mujer estereotipada, ya sea por ser un único objeto de deseo sexual o por tener un nulo protagonismo; el videojuego estaría fomentando los roles sexuales tradicionales.

- Además, en este tipo de género de videojuegos, sería impensable pensar que la protagonista pudiera realizar todas sus actividades de una manera colaborativa, proactiva y no-violenta.

Por lo tanto, la respuesta a nuestra pregunta es una rotunda negativa, siendo DíezGutiérrez et al. (2004) más extremistas respecto al contenido de los videojuegos analizados, pues aseguran lo siguiente:

"Hemos buscado, analizado, reflexionado... Pero ha sido en buena parte inútil. Tenemos que confesar una cierta frustración. Pues no ha sido posible encontrar entre los videojuegos más usados por jóvenes y adolescentes algún tipo de juego que pudiéramos calificar como realmente valioso. Valioso en el sentido de potenciar valores que consideramos socialmente aceptados y que, por eso, serían juegos realmente educativos. No porque añadan contenidos específicamente didácticos, sino porque en el propio desarrollo del juego que plantean los valores que promueven son positivos, o al menos no sexistas en el amplio sentido de la palabra que aquí hemos utilizado" (Díez-Gutiérrez et al., 2004: 433).

A pesar de usar cuestionarios, realizar estudios de casos, grupos de discusión, entrevistas, estudios de campo y análisis documentales (Díez-Gutiérrez et al., 2004), es obvio que la perspectiva científica de un agente externo, aunque éste agente sea un experto en la materia, a veces, puede ser menos detallada que la de un simple aficionado a los videojuegos, y aunque éste sea lego en la disciplina científica, si alcanza a leer algunos estudios, estas personas pueden tener la probable y equivocada sensación de que los expertos realmente no han comprendido los productos que estudian, pues simplemente no los han jugado.

Como afirmación de esto último comentado, se va a citar a continuación dos hechos puntuales de dos videojuegos (de dos géneros distintos: uno de lucha y otro de rol) que fueron muy populares en la España de la última década del siglo XX y que a nivel académico nunca fueron analizados, siendo datos inéditos para la comunidad científica 
mientras que para cualquier persona que haya tenido en sus manos esos dos juegos y los usara con cierta profundidad, será una información más que evidente y conocida por la comunidad de jugadores, pues conocen toda la temática que se va a tratar.

\section{La experiencia personal de un jugador de videojuegos vs. el observador externo}

Finalmente, a través de este mismo método subjetivo, presentamos información inédita de dos videojuegos, de gran popularidad en nuestro país a finales de los años 90: Killer Instinct (juego que fue analizado en múltiples estudios y que presenta violencia sexista explícita) e Illusion of Time (juego que presenta violencia sexista implícita).

\subsection{Killer Instinct: cuando la violencia y el sexismo es más que evidente}

Killer Instinct es uno de los clásicos videojuegos de pelea 1 vs. 1, que podría ser clasificado como un videojuego de combate (FAD, 2002 citada en Díez-Gutiérrez et al., 2004) que presenta características similares a los juegos de este género: "el esquema prototípico de argumento insustancial como excusa para mostrar la lucha" (Díez-Gutiérrez et al., 2004: 182), siendo un videojuego menos violento que Mortal Kombat pero mucho más que Street Fighter, este juego fue producido por la prestigiosa compañía desarrolladora Rare para la Super Nintendo (aunque también fue desarrollado para máquinas recreativas y para videoconsolas portátiles), teniendo una muy buena acogida en el mercado (Dill y Dill, 1999); por lo que posteriormente se desarrollarían continuaciones del mismo. En definitiva, para su época, Killer Instinct fue uno de los mejores productos de las videoconsolas de 16 bits (Belli y López, 2008), pues presentaba unos magníficos gráficos, una gran jugabilidad y una brillante banda sonora, explicándose la nula innovación argumental del videojuego, en parte, al rígido formato que presenta el propio género de videojuegos de luchas entre dos jugadores.

Al igual que otros juegos de lucha (como Mortal Kombat), Killer Instinct tiene una serie de ataques finales violentos que el personaje puede realizar cuando su rival es derrotado, ataque que el personaje puede realizar solo si el jugador conoce la combinación correcta de botones. La única protagonista femenina de esta franquicia, Orchid (protagonista que podemos asociar con Chun-Li, de Street Fighter), es una joven y atractiva mujer, que al igual que la primera Lara Croft, está hipersexualizada; pues está vestida con ropa ajustada y provocativa, representando el estereotipo de mujer-fatal. Esta mujer puede realizar dos últimos ataques de este tipo: en el primero de ellos, puede convertir a su enemigo en una especie de rana y aplastarla de un salto; mientras que en el segundo, el personaje se gira, dando la espalda a la cámara, y enseñando sus pechos al contrario, lo que 
provoca que a su rival se le salgan los ojos de sus órbitas por la sorpresa (Imagen 1) y a continuación, muere por la emoción causada.

Si bien Orchid es la única mujer en el juego; éste permite que dos jugadores usen el mismo personaje, por lo que si esta situación se repite con dos mujeres, la Orchid derrotada responde mostrando un evidente enfado y una clara resignación por la conducta que ha realizado su enemiga, como si tuviera envidia de los prominentes pechos de su adversaria.

El objetivo de este artículo no es el de centrarse en un hecho que podría ser tildado como anecdótico, pues el objetivo real es el distinguir los datos que proceden de varias revisiones que se han realizado sobre los juegos violentos y los efectos que causan (Greitemeyer y Mügge, 2014), incluyendo análisis de varios juegos de lucha de forma individualizada, como el famoso Tekken (Díez-Gutiérrez et al., 2004) y juegos más actuales como Dead or Alive. Se debe tener cautela, pero este ejemplo de violencia sexista y tratamiento de la mujer como un mero objeto sexual nunca fue recogido por ninguna publicación científica seria, mientras que todas las personas que jugaron con este producto, de sobra conocían esta información.

\section{Imagen 1. Segundo Fatality de Orchid}

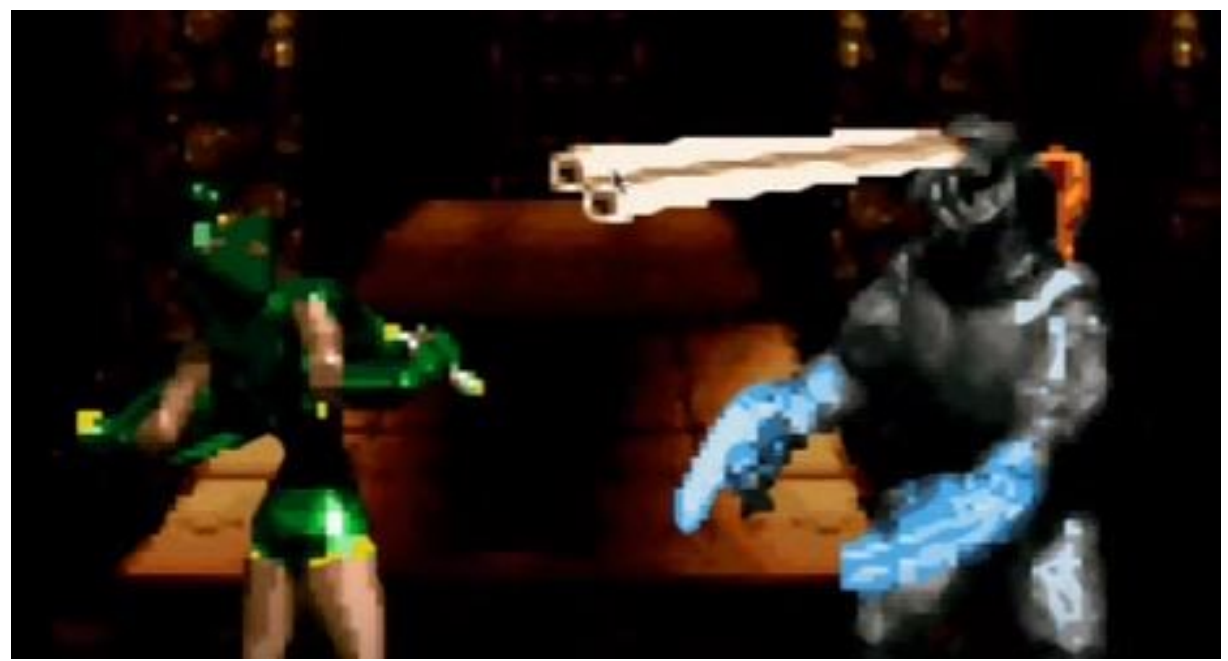

Fuente: https://www.youtube.com/watch?v=F_oLXh2svUc

\subsection{Illusion of Time: violencia sexista sutil o argumento adulto en un juego juvenil}

Illusion of Time (Illusion of Gaia en EE.UU y Gaia Gensōki en Japón), fue el primer videojuego de rol (RPG o Role Playing Game) que llegó a España totalmente traducido al idioma castellano, en el año 1995 (Muñoz, 2008), pues los juegos de esta temática, necesitan ser traducidos, ya que suelen tener unos argumentos bastante elaborados y requieren que el jugador comprenda claramente la historia de los mismos. De igual manera que otros videojuegos de rol, 
en Illusion of Time (juego distribuido por Enix y producido por Quintet), el protagonista va adoptando diferentes roles y consigue aumentar sus propios puntos de experiencia, mejorando progresivamente sus propias habilidades; las tareas que debe realizar para conseguir estas mejoras, en parte, lo decide el propio usuario; pues en este tipo de juegos "el jugador tiene siempre un cierto margen de libertad en su elección y/o en el orden de abordarlas" (Pérez, 2011: 137). El argumento del juego no es relevante, pero se necesita describir concienzudamente algunos contextos específicos del mismo para poder desarrollar la idea que se pretende plasmar en este artículo.

El protagonista del juego, Will, el hijo de un explorador que ha desaparecido en una expedición, es un joven con poderes psíquicos que vive apaciblemente con sus abuelos en una tranquila ciudad costera hasta que por múltiples circunstancias, se ve forzado a realizar un viaje al exterior de la ciudad con sus amigos, en búsqueda de su padre y de una serie de estatuas; las cuales se encuentran en determinadas ruinas arqueológicas. Con el transcurrir de la aventura, Will recorre múltiples lugares y conoce a muchas personas, y como es obvio en este género de videojuegos, tiene que superar una multitud de peligros, retos y enigmas. Uno de estos lugares a los que el protagonista del videojuego llega, es la ciudad de Freejia, una ciudad aparentemente acogedora, pero que una de sus fundamentales actividades económicas es el comercio de esclavos. En este entorno, Will conoce en el mercado de esclavos a tres jóvenes hermanos cautivos que deben trabajar en una mina cercana en condiciones de extrema dureza (la temática de la esclavitud volverá a aparecer en el juego en otra ciudad, Euro, donde una gran multinacional, en secreto también se lucra con el trafico de esclavos, si bien en el juego, el término esclavo se sustituye siempre por la palabra trabajador.

Volviendo a la primera ciudad, Freejia, hay dos aspectos del juego que son desconocidos por los especialistas pero que cualquier jugador asume como algo trivial:

Will, en una charla con dos esclavistas (los cuales son reconocibles por vestir largas túnicas moradas) es preguntado por si conoce el paradero de un esclavo fugitivo, ofreciendo una buena recompensa a la primera persona que de un indicio correcto de su localización. Si el jugador ha pasado previamente por la casa donde el esclavo estaba escondido y vuelve a hablar con el mismo traficante de personas, tiene dos posibilidades: o decirle la verdad y recibir la recompensa, o mentir (o directamente no hablar con el esclavista); si el jugador realiza la primera acción, tanto el dueño de la casa como el esclavo habrán desaparecido, ero si el jugador elige ocultar el paradero del esclavo, éste jamás obtendrá la recompensa, una joya roja ojeto muy valioso. Es llamativo que el juego premie una acción tan cruel y tan ruin como la de desvelar la situación de un esclavo prófugo, a pesar de que éste le comente a Will que su preocupación no era por su situación personal, sino que temía lo que le pudiera pasar al dueño de la casa que lo estaba ocultando en el caso de que ambos fueran descubiertos.

La segunda situación interesante que ofrece este entorno, y que se destaca en este trabajo por su ambiente misterioso y turbio, es que en la misma ciudad, existe una zona oculta, de acceso remoto y que es muy difícil de encontrar (sin ayuda de manuales), incluso para los 
jugadores experimentados; donde Will se encuentra con otro esclavista que le comenta lo siguiente (Imagen 2):

"Ja, ja, ja. Entiendes este lugar. A veces lo que parece poco importante es la cosa más importante. La vida es así. Esto es un regalo. Por favor acéptalo" (a continuación se abre otra ventana de diálogo donde el juego nos revela la siguiente información: “ ¡El viejo mete algo en los bolsillos de Will!" (El regalo resulta ser otra joya roja).

\section{Imagen 2. El encuentro de Will con el esclavista}

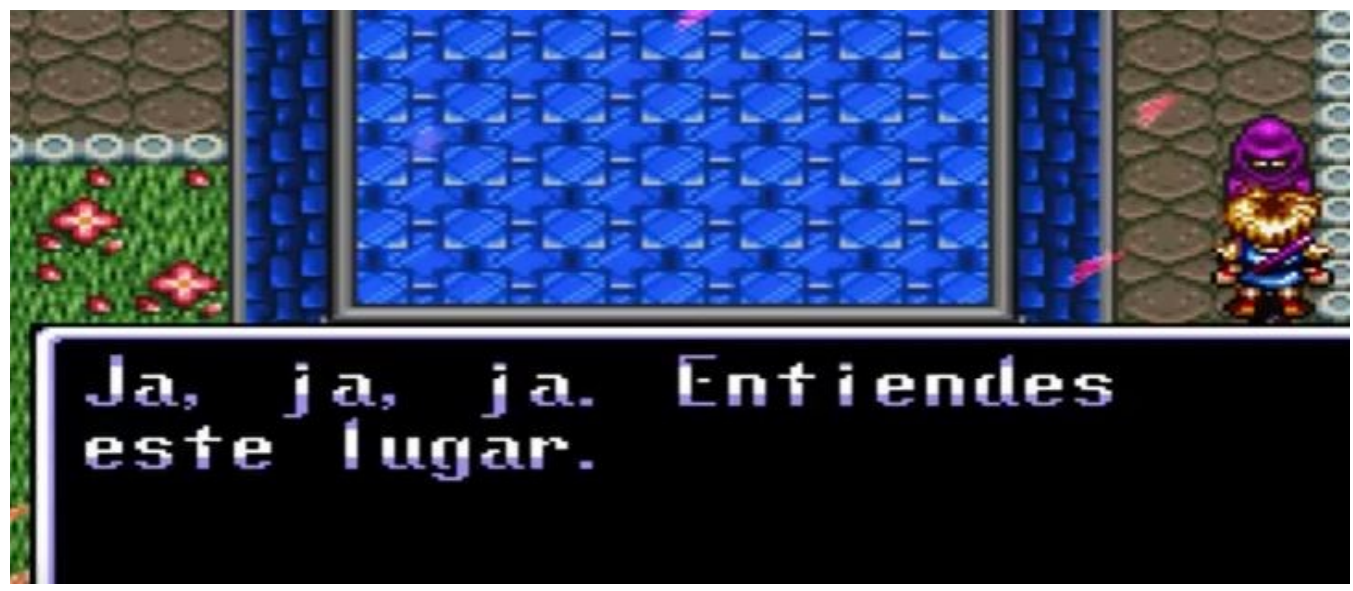

Fuente: https://www.youtube.com/watch? $v=S B 5 C I \_1 S W f w$

Si se recapitula todo lo dicho, en esta ocasión el videojuego nos presenta a una persona mayor que hace un regalo muy valioso a un menor de edad que acaba de conocer sin pedir aparentemente nada a cambio, dedicándose (supuestamente) esta persona al tráfico de esclavos; el cual, se encontraba además en una zona muy escondida de la ciudad. Las únicas interpretaciones coherentes que se le pueden dar a esta situación es la de un ambiente relacionado con el abuso de menores o la trata de blancas.

\section{Conclusiones finales}

La pretensión final de este artículo no es otro que el de abrir un profundo debate acerca el nivel de conocimiento al que pueden llegar los estudios científicos relacionados con los videojuegos y no su deslegitimización, pues si todos los artículos científicos se basaran en los conocimientos subjetivos personales obtenidos por haberlos jugado previamente, la ciencia apenas tendría recorrido en este campo. 
Ejemplos como los presentados en este artículo muestran la paradoja que se da en muchas revisiones de investigadores sociales que encuentran actitudes violentas en los videojuegos, informando de sus hallazgos, los cuales no son tales para los jugadores [véase como ejemplo la situación de las prostitutas que describe Díez-Gutiérrez et al. (2004); Diez-Gutiérrez (2014) en el juego Grand Theft Auto, donde el propio juego recompensa la acción de matar a estas personas al poder robarle el dinero que habían conseguido con su actividad], al resto de la comunidad científica mientras que para las personas que desconocen las características de este tipo de material, al escuchar estas informaciones pueden responder ante los videojuegos con un alarmismo innecesario y acusar a estos productos de fomentar la violencia; ya que como comentan Páez, Fernández, Ubillos y Zubieta (2004: 570) “el aprendizaje por imitación de actos violentos a través de los mass media es otro mecanismo plausible de refuerzo de estos escenarios agresivos y de incitación a la violencia", pero Clemente (2011) también recuerda que la exposición a modelos agresivos no asegura automáticamente el aprendizaje por observación, pues éste también depende de las consecuencias de ese acto agresivo.

El camino de los estudios científicos de los videojuegos debe ir emparejado con los avances tecnológicos, pues el investigador no debe únicamente ponerse en la piel del jugador y tratar de comprender un mundo tan amplio, general y difuso como los videojuegos, los cuales no han sido diseñados para él, pues en la actualidad, en Internet ya se encuentra toda la información y las opiniones que los jugadores comentan de primera mano de los juegos con los que pasan su tiempo de ocio a través de vídeos, blogs, chats, etc.

\section{BIBLIOGRAFÍA}

- Ameneiros, Aida y Ricoy, María-Carmen (2015): "Los videojuegos en la adolescencia: prácticas y polémicas asociadas". En Revista de Estudios e Investigación en Psicología y Educación, no ${ }^{\circ}$ 13, pp. 115-119, [en línea] Disponible en: 10.17979/reipe.2015.0.13.451 [19/05/2016].

- Belli, Simone y López, Cristián (2008): "Breve historia de los videojuegos". En Athenea Digital, $\mathrm{n}^{\circ} .14$, pp. 159-179.

- Burguess, Melinda; Stermer, Steven y Burguess, Stephen (2007): "Sex, Lies, and Video Games: The Portrayal of Male and Female Characters on Video Game Covers". En Sex roles, $n^{\circ}$. 57, pp. 419-433, [en línea] Disponible en: 10.1007/s11199-007-9250-0 [19/05/2016].

- Clemente, Miguel (2011): Fundamentos y principios de psicología jurídica. Madrid: Pirámide.

- Del Moral, María-Esther (2001): 'Los videojuegos con 'chicas' y 'para chicas' de Lara Croft a Barbie”. En Comunicación y pedagogía: Nuevas tecnologías y recursos didácticos, nº 172, pp. 45-50.

- Díez-Gutiérrez, Enrique-Javier (coord.) et al. (2004): La diferencia sexual en el análisis de los videojuegos. Madrid: CIDE/Instituto de la Mujer. 
- Díez-Gutiérrez, Enrique-Javier (2014): "Video games and gender-based violence". En Procedia-Social and Behavioral Sciences, $\mathrm{n}^{\mathrm{o}}$. pp. 132, 58-64.

- Díez-Gutiérrez, Enrique-Javier, Terrón, Eloína y Rojo, Javier (2001): “Videojuegos: cuando la violencia vende". En Cuadernos de Pedagogía, nº. 305, pp. 79-83.

- Dill, Karen y Dill, Jody (1998): "Video game violence: a review of the empirical literature". En Aggression and Violent Behavior, vol. 4, nº 3, pp. 407-428.

- Greitemeyer, Tobias y Mügge, Dirk (2014): "Video Games Do Affect Social Outcomes:A Meta-Analytic Review of the Effects of Violent and Prosocial Video Game Play". En: Personality and Social Psychology Bulletin, vol. 5, nº 40, pp. 578-589, [en línea] Disponible en: 10.1177/0146167213520459 [19/05/2016].

- Grigsby, Mary (1998): "Sailormoon: Manga (comics) and anime (cartoon) superheroine meets Barbie: Global entertainment commodity comes to the United States". En: Journal of Popular Culture, vol. 1, nº 32, pp. 59-80.

- Guerra, Jorge y Revuelta, Francisco-Ignacio (2015): "Visión y tratamiento educativo de los roles masculino y femenino desde el punto de vista de los videojugadores: tecnologías emergentes de la igualdad de género. En Revista Qurriculum, nº. 28, pp. 145-163.

- Kearney, Paul y Pivec, Maja (2007): "Sex, lies and video games". En: British Journal of Educational Technology, vol, 3, $\mathrm{n}^{\circ} .38$, pp. 489-501, [en línea] Disponible en 10.1111/j.14678535.2007.00712.x [19/05/2016].

- Kennedy, Helen (2002): "Lara Croft: Feminist Icon or Cyberbimbo? On the Limits of Textual Analysis". En: The International Journal of Computer Game Research, vol. 2, n . 2.

- Lambert, Yamil y Villota, Wellington (2013): "Difusión de los géneros, características, plataformas, herramientas de desarrollo que se usan en la industria de los video-juegos". En: Revista Tecnológica ESPOL-RTE, vol. 2, nº. 26, pp. 44-51.

- López-Zafra, Esther (2007): “Elaboración de una escala para medir Cultura del Honor". En: Revista de Psicología Social, $\mathrm{n}^{\mathrm{o}}$. 22, pp. 31-42, [en línea] Disponible en 10.1174/021347407779697520 [19/05/2016].

- Millán, Pedro-Javier (2001): "Lara Croft en el paradigma transtextual de las industrias culturales”. En: IX Simposio Internacional de la Asociación Andaluza de Semiótica, pp. 569-575.

- Muñoz, Pablo (2008): "En torno a la localización de videojuegos clásicos mediante técnicas de romhacking: particularidades, calidad y aspectos legales". En: The Journal of Specialised Translation, $\mathrm{n}^{\circ} .9$, pp. 80-95.

- Navarrete, José-Luis; Gómez, Francisco-Javier y Pérez, José-Patricio (2014): “Una aproximación a los paradigmas de la Teoría del Videojuego". En: Zer, vol. 37, n. 19, pp. 107-121.

- Páez, Darío; Fernández, Itziar; Ubillos, Silvia y Zubieta, Elena (2004) (coords.): Psicología Social, Cultura y Educación. Madrid: Pearson Educación.

- Pérez, Óliver (2011): “Géneros de juegos y videojuegos. Una aproximación desde diversas perspectivas teóricas”. En: Comunicació: Revista de Recerca i d'Anàlisi, vol. 1, no . 28, pp. 127146, [en línea] Disponible en 10.2436/20.3008.01.81 [19/05/2016].

- Periodista Digital (2006): "La sexta retira la polémica serie de manga erótico". En: Periodista Digital, 27 de septiembre, [en línea] Disponible en: http://blogs.periodistadigital.com/electroduende.php/2006/09/27/la_sexta_retira_la_polemica_s erie_de_man [19/05/2016].

- Yao, Mike; Mahood, Chad y Linz, Daniel (2009): "Sexual Priming, Gender Stereotyping, and Likelihood to Sexually Harass: Examining the Cognitive Effects of Playing a SexuallyExplicit Video Game". En: Sex roles, $\mathrm{n}^{\circ}$. 62, pp. 77-88, [en línea] Disponible en 10.1007/s11199-009-9695-4 [19/05/2016]. 